\title{
Front Matter: Volume 10820
}

, "Front Matter: Volume 10820," Proc. SPIE 10820, Optics in Health Care and Biomedical Optics VIII, 1082001 (5 November 2018); doi:

$10.1117 / 12.2520377$

SPIE. Event: SPIE/COS Photonics Asia, 2018, Beijing, China 


\title{
Optics in Health Care and Biomedical Optics VIII
}

\author{
Qingming Luo \\ Xingde Li \\ Ying Gu \\ Yuguo Tang \\ Dan Zhu \\ Editors
}

\section{1-13 October 2018 \\ Beijing, China}

Sponsored by

SPIE

COS-Chinese Optical Society

\section{Cooperating Organizations}

Tsinghua University (China) • Peking University (China) • University of Science and Technology of China (China) Zhejiang University (China) - Tianjin University (China) - Beijing Institute of Technology (China) • Beijing University of Posts and Telecommunications (China) - Nankai University (China) - Changchun University of Science and Technology (China) • University of Shanghai for Science and Technology (China) • Capital Normal University (China) • Huazhong University of Science and Technology (China) - Beijing Jiaotong University (China) - Shanghai Institute of Optics and Fine Mechanics (China) - Changchun Institute of Optics and Fine Mechanics (China) - Institute of Semiconductors (China) - Institute of Optics and Electronics (China) - Institute of Physics (China) - Shanghai Institute of Technical Physics (China) • China Instrument and Control Society (China) - Optoelectronics Technology Committee, COS (China) • Optical Society of Japan (Japan) • Optical Society of Korea (Korea, Republic of) - The Australian Optical Society (Australia) • Optics and Photonics Society of Singapore (Singapore) • European Optical Society

Supporting Organizations

CAST_China Association for Science and Technology (China)

NSFC-National Nature Science Foundation (China)

Published by

SPIE

Volume 10820 
The papers in this volume were part of the technical conference cited on the cover and title page. Papers were selected and subject to review by the editors and conference program committee. Some conference presentations may not be available for publication. Additional papers and presentation recordings may be available online in the SPIE Digital Library at SPIEDigitalLibrary.org.

The papers reflect the work and thoughts of the authors and are published herein as submitted. The publisher is not responsible for the validity of the information or for any outcomes resulting from reliance thereon.

Please use the following format to cite material from these proceedings:

Author(s), "Title of Paper," in Optics in Health Care and Biomedical Optics VIII, edited by Qingming Luo, Xingde Li, Ying Gu, Yuguo Tang, Dan Zhu, Proceedings of SPIE Vol. 10820 (SPIE, Bellingham, WA, 2018) Seven-digit Article CID Number.

ISSN: 0277-786X

ISSN: 1996-756X (electronic)

ISBN: 9781510622388

ISBN: 9781510622395 (electronic)

Published by

SPIE

P.O. Box 10, Bellingham, Washington 98227-0010 USA

Telephone +1 3606763290 (Pacific Time) · Fax +1 3606471445

SPIE.org

Copyright @ 2018 , Society of Photo-Optical Instrumentation Engineers.

Copying of material in this book for internal or personal use, or for the internal or personal use of specific clients, beyond the fair use provisions granted by the U.S. Copyright Law is authorized by SPIE subject to payment of copying fees. The Transactional Reporting Service base fee for this volume is $\$ 18.00$ per article (or portion thereof), which should be paid directly to the Copyright Clearance Center (CCC), 222 Rosewood Drive, Danvers, MA 01923. Payment may also be made electronically through CCC Online at copyright.com. Other copying for republication, resale, advertising or promotion, or any form of systematic or multiple reproduction of any material in this book is prohibited except with permission in writing from the publisher. The CCC fee code is 0277$786 \mathrm{X} / 18 / \$ 18.00$.

Printed in the United States of America.

Publication of record for individual papers is online in the SPIE Digital Library.

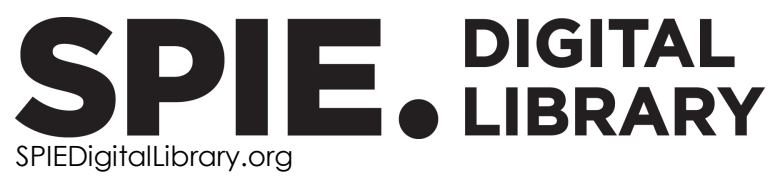

Paper Numbering: Proceedings of SPIE follow an e-First publication model. A unique citation identifier (CID) number is assigned to each article at the time of publication. Utilization of CIDs allows articles to be fully citable as soon as they are published online, and connects the same identifier to all online and print versions of the publication. SPIE uses a seven-digit CID article numbering system structured as follows:

- The first five digits correspond to the SPIE volume number.

- The last two digits indicate publication order within the volume using a Base 36 numbering system employing both numerals and letters. These two-number sets start with 00, 01, 02, 03, 04, 05, 06, 07, 08, 09, OA, OB ... 0Z, followed by 10-1Z, 20-2Z, etc. The CID Number appears on each page of the manuscript. 


\title{
Contents
}

\author{
ix Authors \\ xiii Symposium Committees \\ xvii Conference Committee
}

PHOTON THERAPEUTICS II

1082009 Compare the therapeutic effectiveness of photodynamic therapy with $980 \mathrm{~nm}$ laser on cervical intraepithelial neoplasia (Invited Paper) [10820-7]

$10820 \mathrm{OB}$ Time dependence of myocardial cell necrosis during photodynamic therapy with various photosensitizer contact time [10820-9]

\section{BIOMEDICAL SPECTROSCOPY FOR DIAGNOSTICS}

$10820 \mathrm{OL} \quad$ Comparative study between diagnostic mediums: human tissue and saliva for oral cancer detection using Stokes shift spectroscopy [10820-19]

\section{ADVANCED OPTICAL TECHNIQUES FOR DIAGNOSTICS I}

1082000 Detection of various Thrombin concentrations using etched fiber Bragg gratings functionalized with DNA aptamer [10820-22]

$10820 \mathrm{OP}$ The influence of bilirubin and creatinine on the refractive index of whole blood in terahertz frequency range: a qualitative analysis [10820-23]

$108200 Q$ Quantitative single-exposure laser speckle contrast imaging [10820-24]

10820 OT Smart dental detector [10820-28]

\section{ADVANCED OPTICAL TECHNIQUES FOR DIAGNOSTICS II}

10820 oU Calcified plaque segmentation of intracoronary optical coherence tomography images based on LBF (Invited Paper) [10820-29]

$10820 \mathrm{OV}$ In vivo measurement of retinal neurovascular changes with transcorneal electrical stimulation using optical coherence tomography [10820-30] 
10820 0X Segmentation of diabetic macular edema for retinal OCT images [10820-32]

POSTER SESSION

1082013 Vessel extraction from angiography image using dictionary inpainting [10820-38]

1082014 Measuring temperature-induced effective attenuation coefficient spectra of biological tissue based on diffuse reflection spectroscopy [10820-39]

1082015 Monitoring of blood protein using double slot hybrid plasmonic waveguide [10820-40]

1082017 Antioxidant, anti-inflammatory, and immunostimulatory activity of polysaccharide from artemisiae argyi folium [10820-43]

10820 1B Determination of aloin in aloe extracts from different companies by HPLC-UV [10820-47]

$108201 \mathrm{C}$ Numerical analysis of optical super-resolution in a structure of quasi-Luneburg-sphere [10820-48]

$10820 \mathrm{IE} \quad$ Effects of multiple factors on the photoacoustic detection of glucose based on artificial neural network [10820-50]

$10820 \mathrm{lF} \quad$ Multiphoton imaging of gastric intestinal metaplasia [10820-51]

$1082011 \quad$ Testing of display color causing excitation in eye periphery creating nonlinear distortions of psychophysical response [10820-54]

$10820 \mathrm{lJ}$ Cellular phase observations and measurements on red blood cells affected by lithium and lead ions with quantitative interferometric microscopy [10820-55]

$108201 \mathrm{M}$ Digital field-of-view correction for dual-view transport-of-intensity equation-based quantitative microscopy [10820-58]

$108201 \mathrm{~N} \quad$ High speed and large effective range autofocusing based on numerical wavefront propagation [10820-59]

10820 IR Application of photodynamic fluorescence diagnosis in skin tumors [10820-63]

10820 is Quantitative measurements of gastric cancers based on spectrum-resolved multiphoton imaging [10820-64]

10820 IT Detection of oligomerization of Epstein-Barr virus oncoprotein LMP1 by FRET-based probes [10820-65]

$108201 \mathrm{U}$ Combining EMD with ICA for photoacoustic imaging denoising [10820-66]

$108201 \mathrm{~V}$ Quantitative FRET measurement of the interaction of $A_{1}$ adenosine receptors and $A_{2} A$ adenosine receptors in living cell [10820-67] 
$10820 \mathrm{lW}$ In-line taper fiber-optic interferometer and FBG for label-free detection of cancer biomarker [10820-68]

$108201 \mathrm{X} \quad$ Label-free multiphoton microscopy for ex vivo brain imaging: toward assisting pathologic diagnosis [10820-69]

1082020 Modified optical coefficient measurements using a single high-NA fiber with detection parameter changes at a tip [10820-72]

$1082021 \quad$ Photoacoustic classification of tumor malignancy based on support vector machine [10820-73]

1082023 Deep learning for super-resolution localization microscopy [10820-75]

1082024 3D measurement of collagen directional variance in ovarian cancer by multiphoton microscopy [10820-76]

1082027 Diagnosis for photoacoustic breast cancer images with machine learning [10820-79]

$1082028 \quad$ Improved super-resolution optical fluctuation imaging by multiple sparse Bayesian learning method [10820-80]

1082029 Metronidazole-substituted dendrimer silicon phthalocyanine: a novel photodynamic therapy photosensitizer [10820-81]

$108202 \mathrm{D} \quad$ Illumination and projection optics for spatial frequency domain fluorescence imaging [10820-85]

$108202 \mathrm{G} \quad$ Collagen reversible denaturation by a weak near-infrared laser light irradiation for vascular softening [10820-89]

$108202 \mathrm{H} \quad$ Simulation of the dose control for vascular targeted photodynamic therapy [10820-90]

$1082021 \quad$ The approach for quantification assessment for port-wine stains in three-dimensional and color space [10820-91]

10820 2K Defection of dental carious lesions by swept-source optical coherence tomography [10820-93]

10820 2M Effect of PSF on super-resolution ultrasound imaging implemented by bSOFI method [10820-95]

1082020 Assessment of tissues' inhomogeneous optical properties by a cost-effective microscope based on LED illumination [10820-97]

$108202 \mathrm{P} \quad$ Effects of substrate stiffness on the elasticity of ovarian cells using atomic force microscopy [10820-98]

$108202 R \quad$ Effect of oxidative stress stimulation on intracellular PTEN trafficking in ovarian cancer by fluorescence correlation spectroscopy [10820-100]

$1082025 \quad$ Optical fiber detection system for sensing singlet oxygen luminescence in aqueous solution [10820-101] 
$108202 T$ Spatial autocorrelation of Mueller matrix images as indicator of cervical pre-cancer detection [10820-102]

$108202 \mathrm{U} \quad$ Photoacoustic imaging with custom-designed fingertip laser diode [10820-103]

$108202 \mathrm{~V}$ Programme to improve systems resolution in multiconfiguration sensors [10820-104]

$108202 \mathrm{~W} \quad$ Numerical simulation and experimental study on photo-thermal damage distribution of skin [10820-105]

$108202 X \quad$ Determination optical properties of tissue-like phantoms using diffuse reflectance and transmittance spectroscopy [10820-106]

$108202 Y$ Photoacoustic sensing and imaging by sharing single data acquisition channel [10820-107]

$108202 Z$ Characterization of the germination kinetics of individual Nosema bombycis spores using phase contrast microscopy imaging and Raman spectroscopy [10820-108]

1082032 The study of optical properties and spectral characteristics of brain glioblastoma and lung adenocarcinoma [10820-112]

1082033 Dual-contrast nonlinear photoacoustic sensing based on quasi-CW single-pulsed laser [10820-113]

1082034 Simulation of light absorption in tumor-embedded uterus filled with strong scattering media by diffused light sources [10820-114]

1082035 Photoacoustic imaging of gastric cancer in vitro based on water-soluble nanoscale gold rods [10820-115]

1082036 Cuff-less blood pressure measurement using fingertip photoplethysmogram signals and physiological characteristics [10820-116]

1082037 In vivo imaging prednisolone-induced osteoporosis of the adult zebrafish with spectral domain optical coherence tomography [10820-117]

1082038 Wrist pulse signal acquisition by video motion processing [10820-118]

1082039 FEM simulation of laser-generated ultrasonic waves in human skin in different epidermal thickness [10820-119]

10820 3A Detection of tilted fiber Bragg grating fiber-optic sensors with short-term KLT: towards low-cost biosensors [10820-120]

$108203 \mathrm{~B} \quad$ An etched chirped fiber Bragg grating for measurement of refractive index and temperature pattern [10820-121]

10820 3C Evaluation of singlet oxygen luminescence of a novel chlorin photosensitizer [10820-122]

10820 3D Label-free imaging using multimodal microscopy in vivo and in vitro [10820-123] 
$108203 \mathrm{E} \quad$ In vivo monitoring optical clearing process of skin using two-photon microscopy [10820-124]

$108203 \mathrm{~F} \quad$ Method of detection of resting heart rate based on imaging photoplethysmography technology [10820-125]

$108203 \mathrm{G}$ The impact of optical radiation of femtosecond duration on human glial cells [10820-126]

$1082031 \quad$ Impacts of vascular diameter and depth on singlet oxygen luminescence imaging in tissue simulating phantom [10820-128]

$108203 \mathrm{~J} \quad$ Esophageal cancer detection based on two-photon excitation fluorescence combined with membrane electrophoresis of blood serum [10820-129]

$108203 \mathrm{~K}$ The effects of water-mediated cavitation on hard tissue ablation with Ho:YAG laser [10820-130]

10820 3L Detection of limb ischemia based on Eulerian Video Magnification [10820-131]

$108203 \mathrm{M}$ Pigmented skin lesion segmentation based on random forest and full convolutional neural networks [10820-132]

1082030 Finite element simulation of pulsed laser-induced thermotherapy for biological liver tissue [10820-134]

$108203 P$ Distributed strain sensing medical catheter for epidural anesthesia [10820-135] 
Proc. of SPIE Vol. $108201082001-8$

Downloaded From: https://www.spiedigitallibrary.org/conference-proceedings-of-spie on 26 Apr 2023 Terms of Use: https://www.spiedigitallibrary.org/terms-of-use 


\section{Authors}

Numbers in the index correspond to the last two digits of the seven-digit citation identifier (CID) article numbering system used in Proceedings of SPIE. The first five digits reflect the volume number. Base 36 numbering is employed for the last two digits and indicates the order of articles within the volume. Numbers start with 00, 01, 02, 03, 04, 05, 06, 07, 08, 09, OA, OB...0Z, followed by 10-1Z, 20-2Z, etc.

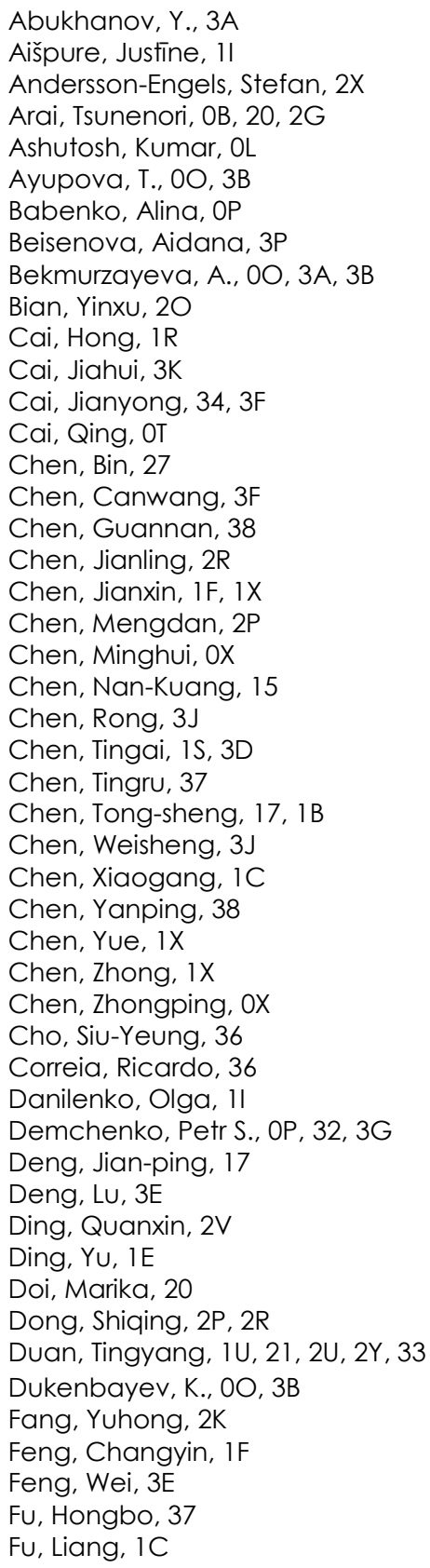


Li, Lianhuang, IF

Li, Qian, OV

Li, Qin, OU, 21

Li, Xi, 1 S

Li, Yongzhen, 3C

Li, Yuling, 28

Li, Zhifang, 34, 35, 30

Liang, Fuqiang, $2 S$

Liao, Jiuling, 3D

Liao, Xianglian, 3I

Lin, Bingbing, $1 \mathrm{X}$

Lin, Hongxin, 24

Lin, Huiyun, 2S, 3l

Lin, Juqiang, IT, IV

Lin, Lisheng, 2D, 2S, 3C, 3I

Lin, Ruolan, $1 \mathrm{X}$

Lin, Yanping, 37

Lin, Yating, 1T, 1V

Lin, Yongping, 34, 30

Lin, Yuanxiang, $1 X$

Liu, Airong, $1 \mathrm{X}$

Liv, Cheng, 1J, 1M, 1N

Liu, Guodong, 1E

Liu, Hua, 2V

Liu, Jin, 14

Liu, Junxian, $2 Z$

Liu, Lina, 2D

Liu, Nenrong, 3J, 3L

Liu, Qiulan, 20

Liu, Wei, OU

Liu, Xin, 23, 28, 2M

Liu, Xueyu, 14

Liu, Ying, 28, 2M

Lu, Huihui, 2X

Lu, Qijing, 1C

Luo, Jianwen, 23

Luo, Limin, 13

Luo, Yanghuan, 34, 30

LV, Minglei, $2 M$

LV, Mingxuan, 3K

Ma, Yunkun, $1 \mathrm{X}$

Meglinski, Igor V., 3G

Meng, Xiang-Ping, 1B

Miao, Zhenbin, $2 Z$

Mo, Yan, 2H, $2 \mathrm{I}$

Molardi, Carlo, 00, 3B, 3P

Morgan, Stephen P., 36

Nakazawa, Haruna, 20

$\mathrm{Ni}$, Ming, 24

Ogawa, Emiyu, OB, 20, 2G

Ozolinsh, Maris, 11

Paulins, Paulis, 11

Peng, Shan, 3M

Peng, Yiru, 29

Porozov, Yuri B., $3 G$

Pradhan, Asima, OL, 2T

Qi, Xiaoyu, 09

Qin, Haotian, 0T

Qin, Xianfu, OX

Qu, Junle, IY
Ren, Zhong, $1 \mathrm{E}$

Shaimerdenova, M., 00, 3A, 3B

Shan, Ning, 39

Shen, Yi, 31

Shi, Aisi, 2P

Shi, Fan, 1B

Shi, Xiaowei, 3K, 3L

Shu, Yuexia, 2M

Singh, Lokendra, 15

Srikarthikeyan, K. K., OQ

Sun, Dandan, IW

Sun, Pengcheng, OV

Sypabekova, M., 00, 3A, 3B

Tang, Xiaoqiong, $2 \mathrm{R}$

Tosi, Daniele, 0O, 3A, 3B, 3P

Unni, Sujatha Narayanan, $0 Q$

Wang, Cheng, OT

Wang, Feng, $1 \mathrm{X}$

Wang, Guangxing, 24, 2K

Wang, Guiwen, $2 Z$

Wang, Haoyu, 35

Wang, Jiao, $2 R$

Wang, Jing, 3L

Wang, Jingbo, OU

Wang, Limei, 37

Wang, Lin, 13

Wang, Luwei, $1 Y$

Wang, Shouyu, 1 J, 1M, 1N

Wang, Shu, $1 \mathrm{X}$

Wang, Xiaochun, $2 Z$

Wang, Xingfu, $1 X$

Wang, Yi-fei, 17, 1B

Wang, Yuhua, 2P

Wang, Zhengchao, $2 R$

Wang, Zhi-ping, 17, 1B

Wei, Chao, 38

Wei, Qi, 1 J, $1 M$

Wen, L., 36

Weng, Cuncheng, 3F

Wilson, Brain C., $2 S$

Wu, Huaqin, 35, 3F

Wu, Huaqing, 2W

Wu, Shulian, 2W, 35, 3F

Wu, Ting, 3D

Wu, Xiang, $1 \mathrm{C}$

Wu, Zhiwei, 1T, 1V

Wu, Zi-Cong, 1B

Xia, Haibo, $1 \mathrm{U}$

Xia, Xianyuan, 1S, 3D

Xia, Yang, 13

Xiang, Xiang, 37

Xie, Lizhe, 13

Xie, Shusen, 1C, 1T, 1V, 2K, 2P

Xin, Limei, 09

$\mathrm{Xu}$, Aisheng, 38

$\mathrm{XU}$, Jianshu, $\mathrm{V} \mathrm{V}$

$X U$, Jing, $1 M, 1 N$

$\mathrm{Xu}$, Xuelin, $2 S$

Xue, Liang, $1 \mathrm{~J}$

Yan, Bin, 13 
Yan, Keding, $1 \mathrm{~J}$

Yan, Wei, IY

Yang, Hongqin, 29, 2P, 2R

Yang, Mei, OT

Yang, S., 36

Yang, Tiejun, 3M

Yang, Zhigang, $1 Y$

Ye, Qing, $1 T$

Ye, Qiuhao, 29

YU, Biying, 3F

Yu, Haotian, 38

Yu, Jia, 3D

YU, Tingting, 3E

Yu, Yunfei, 31

Yuan, Hui, 3L

Yun, Hui, 3K

Zaffar, Mohammad, 2T

Zeng, Di, 29

Zhan, Ren-Jun, 39

Zhan, Zhenlin, 1F, 2K

Zhang, Jian, 37

Zhang, Jiayao, 27, $2 \mathrm{U}$

Zhang, Jiaying, 09

Zhang, Jixia, $2 \mathrm{H}, 2 \mathrm{I}$

Zhang, Mingyuan, $1 \mathrm{M}$

Zhang, Pengfei, $2 Z$

Zhang, Tianmiao, $\mathrm{OP}, 32$

Zhang, Xianzeng, 3J, 3K, 3L

Zhang, Xiaoman, 3F

Zhang, Y., 36

Zhang, $Y \cup, 2 Z$

Zheng, Hao, OV

Zheng, Mengmeng, IT

Zheng, Wei, 1S, 3D

Zheng, Xiaoling, 24

Zhong, Hongtao, 1U, 21, 2U, 2Y, 33

Zhou, Bo, 39

Zhou, Chuanqing, OV

Zhou, Liwei, 2V

Zhou, Meng, 1U, 21, 27, 2U, 2Y, 33

Zhou, Tianyang, 23

Zhou, Yongjian, $1 \mathrm{~F}$

Zhu, Dan, 3E

Zhu, Xiaogin, $1 \mathrm{X}$

Zhuo, Shuangmu, 1F, 24

Zou, Jian, 3C

Proc. of SPIE Vol. 10820 1082001-11 
Proc. of SPIE Vol. 10820 1082001-12 Downloaded From: https://www.spiedigitallibrary.org/conference-proceedings-of-spie on 26 Apr 2023
Terms of Use: https://www.spiedigitallibrary.org/terms-of-use 


\title{
Symposium Committees
}

\author{
General Chairs \\ Maryellen Giger, President, SPIE and The University of Chicago \\ (United States) \\ Qihuang Gong, President, Chinese Optical Society and Peking \\ University (China)
}

General Co-chairs

Arthur Chiou, National Yang-Ming University (Taiwan, China)

Guangcan Guo, Past President, Chinese Optical Society and University of Science and Technology of China (China)

Zejin Liu, Vice President, Chinese Optical Society and National University of Defense Technology (China)

Technical Program Chairs

Ruxin Li, Vice President, Chinese Optical Society and Shanghai Institute of Optics and Fine Mechanics (China)

Xingde Li, Johns Hopkins University (United States)

Technical Program Co-chairs

Tianchu Li, National Institute of Metrology (China)

Wei Huang, Northwestern Polytechnical University (China)

Ying Gu, Vice President, Chinese Optical Society and PLA General Hospital (China)

Huilin Jiang, Changchun University of Science and Technology (China)

Local Organizing Committee Chair

Xu Liu, Secretary General, Chinese Optical Society and Zhejiang University (China) 
Local Organizing Committee Co-chairs

Wenqing Liu, Vice President, Chinese Optical Society and Anhui Institute of Optics and Fine Mechanics (China)

Guobin Fan, China Academy of Engineering Physics (China)

Local Organizing Committee

Xiaomin Ren, Vice President, Chinese Optical Society and Beijing University of Posts and Telecommunications (China)

Suotang Jia, Vice President, Chinese Optical Society and Shanxi University (China)

Wenjie Wang, Vice President, Chinese Optical Society and Sunny Group Company, Ltd. (China)

Qingming Luo, Huazhong University of Science and Technology (China)

Ping Jia, Changchun Institute of Optics, Fine Mechanics and Physics (China)

Wei Zhao, Xi'an Institute of Optics and Precision Mechanics (China)

Yudong Zhang, Chengdu Branch, Chinese Academy of Sciences (China)

Ninghua Zhu, Institute of Semiconductors (China)

Yongtian Wang, Beijing Institute of Technology (China)

Xiaocong Yuan, Shenzhen University (China)

Limin Tong, Zhejing University (China)

Weimin Chen, Chongqing University (China)

Yidong Huang, Tsinghua University (China)

Tiegen Liu, Tianjin University (China)

Zhiping Zhou, Peking University (China)

Changhe Zhou, Jinan University (China)

Yiping Cui, Southeast University (China)

Zhongwei Fan, Academy of Optoelectronics, CAS (China)

Xiaoying Li, Tianjin University (China)

Yan Li, Deputy Secretary General, Chinese Optical Society and Peking University (China)

Caiwen Ma, Xi' an Institute of Optics and Precision Mechanics (China)

Xinliang Zhang, Huazhong University of Science and Technology (China)

Jianxin Chen, Fujian Normal University (China)

Yihua Hu, College of Electronic Engineering, National Univ. of Defense Technology (China) 
Secretaries-General

Bo Gu, Deputy Secretary General, Chinese Optical Society (China)

Hong Yang, Deputy Secretary General, Chinese Optical Society and

Peking University (China)

Executive Organizing Committee

David J. Bergman, Tel Aviv University (Israel)

Qionghai Dai, Tsinghua University (China)

Keisuke Goda, The University of Tokyo (Japan)

Qihuang Gong, Peking University (China)

Ying Gu, Chinese PLA General Hospital (China)

Guang-Can Guo, University of Science and Technology of China (China)

Byoung S. Ham, Gwangju Institute of Science and Technology

(Korea, Republic of)

Sen Han, University of Shanghai for Science and Technology (China) and Suzhou H\&L Instruments LLC (China)

Werner H. Hofmann, Technische Universität Berlin (Germany)

Minghui Hong, National University of Singapore (Singapore)

Bahram Jalali, University of California, Los Angeles (United States)

Shibin Jiang, AdValue Photonics, Inc. (United States)

Satoshi Kawata, Osaka University (Japan)

Tina E. Kidger, Kidger Optics Associates (United Kingdom)

Baojun Li, Jinan University (China)

Ming Li, Institute of Semiconductors (China)

Ruxin Li, Shanghai Institute of Optics and Fine Mechanics (China)

Xingde Li, Johns Hopkins University (United States)

Jian Liu, PolarOnyx, Inc. (United States)

Tiegen Liu, Tianjin University (China)

Yongfeng Lu, University of Nebraska-Lincoln (United States)

Qingming Luo, Huazhong University of Science and Technology (China)

Yuji Sano, ImPACT (Japan)

Yunlong Sheng, Université Laval (Canada)

Kebin Shi, Peking University (China)

Tsutomu Shimura, The University of Tokyo (Japan)

Upendra N. Singh, NASA Langley Research Center (United States)

Michael G. Somekh, The Hong Kong Polytechnic University

(Hong Kong, China)

Yuguo Tang, Suzhou Institute of Biomedical Engineering and

Technology (China)

Masahiko Tani, University of Fukui (Japan)

Kimio Tatsuno, Koga Research Institute, Ltd. (Japan)

Kevin K. Tsia, The University of Hong Kong (Hong Kong, China)

Kazumi Wada, Massachusetts Institute of Technology (United States) 
Yongtian Wang, Beijing Institute of Technology (China)

Rongshi Xiao, Beijing University of Technology (China)

Hongxing $X \mathbf{U}$, Wuhan University (China)

Toru Yoshizawa, Tokyo University of Agriculture and Technology (Japan) and 3D Associates (Japan)

Changyuan Yu, The Hong Kong Polytechnic University

(Hong Kong, China)

Chongxiu Yu, Beijing University of Posts and Telecommunications (China)

Xiao-Cong Yuan, Shenzhen University (China)

Xiaoyan Zeng, Huazhong University of Science and Technology (China)

Cunlin Zhang, Capital Normal University (China)

Song Zhang, Purdue University (United States)

Xi-Cheng Zhang, University of Rochester (United States)

Xinliang Zhang, Wuhan National Laboratory for Optoelectronics (China)

Xuping Zhang, Nanjing University (China)

Changhe Zhou, Shanghai Institute of Optics and Fine Mechanics (China)

Zhiping Zhou, Peking University (China)

Dan Zhu, Huazhong University of Science and Technology (China)

Ning Hua Zhu, Institute of Semiconductors (China) 


\title{
Conference Committee
}

\author{
Conference Chairs
}

Qingming Luo, Huazhong University of Science and Technology (China)

Xingde Li, Johns Hopkins University (United States)

Ying Gu, Chinese PLA General Hospital (China)

Yuguo Tang, Suzhou Institute of Biomedical Engineering and Technology (China)

\section{Conference Co-chair}

Dan Zhu, Huazhong University of Science and Technology (China)

\section{Conference Program Committee}

Jing Bai, Tsinghua University (China)

Stephen A. Boppart, University of Illinois (United States)

Shih-Chi Chen, The Chinese University of Hong Kong (Hong Kong, China)

Wei R. Chen, University of Central Oklahoma (United States)

Yu Chen, University of Maryland, College Park (United States)

Linhong Deng, Chongqing University (China)

Zhihua Ding, Zhejiang University (China)

Qiyong Gong, West China Hospital (China)

Hui Li, Fujian Normal University (China)

Hong Liu, The University of Oklahoma (United States)

Hui Ma, Tsinghua University (China)

Yingtian Pan, Stony Brook University (United States)

Paras N. Prasad, University at Buffalo (United States)

Yuwen Qin, National Natural Science Foundation (China)

Junle Qu, Shenzhen University (China)

Kebin Shi, Peking University (China)

Jie Tian, Institute of Automation (China)

Valery V. Tuchin, Saratov State University (Russian Federation)

Lihong V. Wang, California Institute of Technology (United States) and Washington University in St Louis (United States)

Ruikang K. Wang, University of Washington (United States)

Xueding Wang, University of Michigan (United States)

Xunbin Wei, Shanghai Jiao Tong University (China)

Xujie Xia, Shanghai Jiao Tong University (China)

Da Xing, South China Normal University (China)

Kexin $\mathbf{X u}$, Tianjin University (China) 
Xibin Yang, Suzhou Institute of Biomedical Engineering and Technology (China)

Yudong Zhang, Institute of Optics and Electronics (China)

Zhenxi Zhang, Xi'an Jiaotong University (China)

\section{Session Chairs}

1 Photon Therapeutics I

Xingde Li, Johns Hopkins University (United States)

2 Photon Therapeutics II

Ying Gu, Chinese PLA General Hospital (China)

3 Microscopy and Imaging for Neurons

Dan Zhu, Huazhong University of Science and Technology (China)

4 Biomedical Spectroscopy for Diagnostics

Dan Zhu, Huazhong University of Science and Technology (China)

5 Advanced Optical Techniques for Diagnostics I

Wei R. Chen, University of Central Oklahoma (United States)

6 Advanced Optical Techniques for Diagnostics II

Xueding Wang, University of Michigan (United States)

7 Nano/Biophotonics

Xueding Wang, University of Michigan (United States) 